\title{
Produce an Analytical Map for the Distribution of Air Pollution by Toxic Gases in Baghdad City by Geographic Information System
}

\author{
Wassan A. Hassan \\ Al-Nahrain Nanorenewable Energy Research Center, Al-Nahrain University, Baghdad-Iraq. \\ Corresponding Author:wassanabd82@gmail.com.
}

\begin{abstract}
Iraq suffers from pollution of the air with many gases, such as carbon dioxide, carbon monoxide, methane, ozone and others. Baghdad governorate was used as an example to measure the amount of air pollution and distribution in the areas of Baghdad and used data for three measurement stations in Baghdad is the station Jadiriya, Andulos and Alwaziriya, which are available only and for three gases are carbon dioxide and carbon monoxide and ozone and 2011 and 2012 and for all months. The study used three methods of mathematical induction (IDW, Kriging and Spline), one of the methods of mathematical induction in GIS programs. Analytical maps of the distribution and distribution of gases were obtained in Baghdad and it became clear that the IDW method is the most accurate of the three methods. [DOI: 10.22401/JNUS.21.2.12]
\end{abstract}

Keywords: toxic gases, interpolation methods.

\section{Introduction}

The atmosphere consists of three layers: troposphere, stratosphere, ionosphere, And human activities in the first layer where air changes occur. The air is composed of nonpolluted air Nitrogen, oxygen and argon with known and specific concentrations do not dissolve for a few concentrations of biodiesel Carbon, neon, helium, hydrogen and water vapor. The expression of air pollution indicates the presence of substances in the air Different concentrations harmful to human health, animals and plants and damage to the environment and soil Sources of these pollutants It may be natural that a person did not cause it or was abnormal. The person caused it as its use Fuel in the industry, transportation, radioactivity and pollution have significant impacts from place to place[1].

Around 2.4 million people die every year due to some reasons attributed to air pollution due to its impact on the hole of Ozone and acid rain. on the one hand. On the other hand, some means of control can be used for handling the Air pollution generated by industry and transportation such as mechanical complexes and electrostatic precipitation filters, gas washing machines and more as listed in table (1) .[2].
Table (1)

Indicative values of independent substances in the air based on non-cancerous effects, odor and disturbance [2].

\begin{tabular}{||c||c||c||}
\hline Subject & Guided Values & $\begin{array}{c}\text { Time for } \\
\text { exposure }\end{array}$ \\
\hline \hline $\mathrm{CO}$ & $100 \mathrm{mg} / \mathrm{m} 3$ & 15 minute \\
\hline \hline $\mathrm{CO} 2$ & $0.4 \mathrm{mg} / \mathrm{m} 3$ & 60 minute \\
\hline $\mathrm{O} 3$ & $\begin{array}{c}0.15-0.20 \\
\mathrm{mg} / \mathrm{m} 3\end{array}$ & 60 minute \\
\hline
\end{tabular}

\subsection{Carbon monoxide (CO)}

It is a gas that has no color or odor; and is the result of incomplete combustion of fuel. It is issued from exhausted Cars are burning coal or firewood in heaters. It is the most dangerous type of air pollution and the most toxic to Human and animal. crystalline carbon monoxide with hemoglobin is a component of carboxylic hemoglobin and thus inhibits Oxygen from the union with hemoglobin in this case deprives the body of oxygen [3].

\subsection{Carbon dioxide(CO2)}

Increasing its concentration leads to difficulty breathing and feeling congested with irritation of mucous membranes and bronchitis Aerobic and throat irritation. Carbon dioxide is made up of organic materials such as paper, wood, coal and oil.

Carbon dioxide is one of the most important contaminants that humans have put into the air. The process of environmental 
equilibrium that dissolves excess carbon dioxide in the sea and ocean waters is acidic Is known as carbonic acid and reacts with some sediments consisting of bicarbonate and calcium carbonate. Plants also contribute much of it to photosynthesis.

It should be noted that excessive use of fuel, cutting forests or reducing green spaces contributed to the rise in carbon dioxide in the atmosphere which could lead to global warming which is known as global warming. [4]

\subsection{Damage to air pollution on the ozone layer}

A poisonous, transparent gas that blurs into blue; and its molecule consists of three oxygen atoms. Ozone is present in the lower troposphere and the stratosphere. Ozone is formed in the lower atmosphere of pollutants from transport or some vehicles Which contain hydrocarbons. In this case, ozone is a dangerous component on human health because breathing a small amount of it causes irritation in the respiratory system and death may occur. Ozone in the upper atmosphere consists of the interaction of oxygen molecules with free oxygen The resulting fission of these particles results from ultraviolet radiation:

$$
\mathrm{O} 2+\mathrm{O} \text { ultra violet } \rightarrow \mathrm{O} 3
$$

\section{Study area}

In this research, the city of Baghdad was chosen due to the high population density, due to the presence of many causes of air pollutants such as factories, laboratories and cars. Using the Google Earth program, a image of the city of Baghdad is taken and the three meteorological stations are projection, as shown Fig.(1).

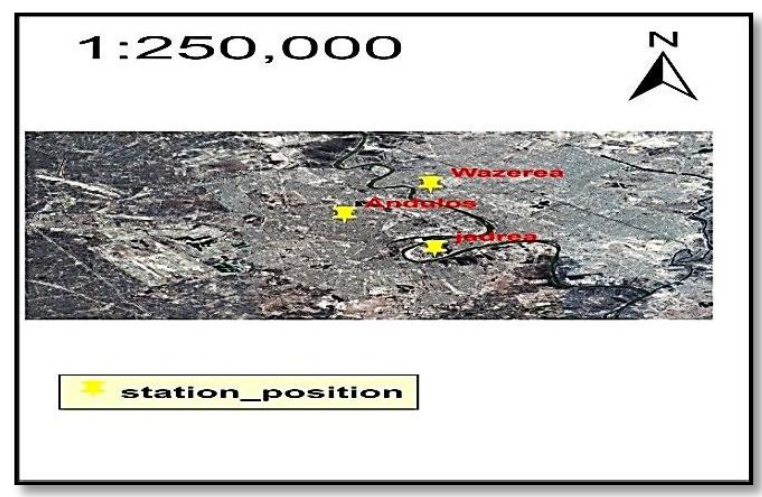

Fig.(1): Show Baghdad image and three meteorological station.

\section{Research problem}

The research attempts to find an analytical map for the distribution of air polluting gases in the city of Baghdad.

\section{Techniques used in research}

In this research, the use of GIS techniques, which are modern technologies and high efficiency. The (ARCMAP 10.2) program is the latest version are used in the research.

\section{Data used in the search}

Monthly data for the time interval 2011 and 2012 and for three monitoring stations in Baghdad was used; they listed in Table (2). 
Table (2)

Data for air quality control stations in Baghdad for 2011 and 2012 [5].

\begin{tabular}{|c|c|c|c|}
\hline \multicolumn{4}{|c|}{ Al Jadiria JAN -2011 } \\
\hline $\mathrm{SO} 2$ & $\mathrm{O} 3$ & $\mathrm{CO}$ & Date \& Time \\
\hline $\mathrm{ppm}$ & ppm & ppm & \\
\hline 0.045 & 0.092 & 0.855 & January \\
\hline 0.032 & 0.099 & 0.615 & February \\
\hline 0.026 & 0.112 & 0.527 & March \\
\hline 0.048 & 0.046 & 0.435 & April \\
\hline 0.042 & 0.044 & 0.452 & May \\
\hline 0.045 & 0.066 & 0.523 & June \\
\hline 0.056 & 0.047 & 0.61 & July \\
\hline 0.043 & 0.077 & 0.61 & August \\
\hline 0.044 & 0.081 & 0.671 & September \\
\hline 0.049 & 0.081 & 0.918 & October \\
\hline 0.037 & 0.068 & 0.726 & November \\
\hline 0.055 & 0.056 & 0.997 & December \\
\hline 0.0435 & 0.072 & 0.661 & The average \\
\hline \multicolumn{4}{|c|}{ Al Waziria JAN -2011 } \\
\hline $\mathrm{SO} 2$ & $\mathrm{O} 3$ & $\mathrm{CO}$ & Date \& Time \\
\hline $\mathrm{ppm}$ & $\mathrm{ppm}$ & $\mathrm{ppm}$ & \\
\hline 0.03 & 0.011 & 0.903 & January \\
\hline 0.026 & 0.021 & 0.661 & February \\
\hline 0.023 & 0.038 & 0.773 & March \\
\hline 0.025 & 0.035 & 0.871 & April \\
\hline 0.04 & 0.034 & 0.787 & May \\
\hline 0.052 & 0.034 & 0.64 & June \\
\hline 0.041 & 0.031 & 0.739 & July \\
\hline 0.048 & 0.022 & 0.552 & August \\
\hline 0.054 & 0.025 & 0.665 & September \\
\hline 0.059 & 0.022 & 0.917 & October \\
\hline 0.041 & 0.015 & 0.952 & November \\
\hline 0.047 & 0.01 & 1.255 & December \\
\hline 0.040 & 0.024 & 0.809 & The average \\
\hline \multicolumn{4}{|c|}{ Al Andlus JAN -2011 } \\
\hline $\mathrm{SO} 2$ & $\mathrm{O} 3$ & $\mathrm{CO}$ & Date \& Time \\
\hline $\mathrm{ppm}$ & ppm & ppm & \\
\hline 0.034 & 0.023 & 0.818 & June \\
\hline 0.037 & 0.021 & 1.21 & July \\
\hline 0.033 & 0.015 & 1.046 & August \\
\hline 0.038 & 0.02 & 1.222 & September \\
\hline 0.034 & 0.021 & 1.061 & October \\
\hline 0.033 & 0.01 & 1.156 & November \\
\hline 0.038 & 0.007 & 1.527 & December \\
\hline 0.035 & 0.016 & 1.148 & The average \\
\hline \multicolumn{4}{|c|}{ Al Jadiria JAN -2012 } \\
\hline $\mathrm{SO} 2$ & $\mathrm{O} 3$ & $\mathrm{CO}$ & Date \& Time \\
\hline $\mathrm{ppm}$ & $\mathrm{ppm}$ & $\mathrm{ppm}$ & \\
\hline 0.05 & 0.06 & 0.928 & January \\
\hline
\end{tabular}




\begin{tabular}{|c|c|c|c|}
\hline 0.036 & 0.05 & 0.653 & February \\
\hline 0.041 & 0.037 & 0.493 & March \\
\hline 0.032 & 0.047 & 0.447 & April \\
\hline 0.048 & 0.034 & 0.436 & "May \\
\hline 0.051 & 0.03 & 0.496 & June \\
\hline 0.049 & 0.042 & 0.705 & July \\
\hline 0.013 & 0.05 & 0.524 & August \\
\hline 0.014 & 0.062 & 0.57 & September \\
\hline 0.01 & 0.051 & 0.54 & October \\
\hline 0.021 & 0.047 & 0.937 & November \\
\hline 0.036 & 0.043 & 0.898 & December \\
\hline 0.033 & 0.046 & 0.635 & The average \\
\hline \multicolumn{4}{|c|}{ Al Waziria JAN -2012 } \\
\hline $\mathrm{SO} 2$ & $\mathrm{O} 3$ & $\mathrm{CO}$ & Date \& Time \\
\hline ppm & $\mathrm{ppm}$ & ppm & \\
\hline 0.053 & 0.011 & 1.495 & January \\
\hline 0.046 & 0.21 & 1.148 & February \\
\hline 0.032 & 0.03 & 0.939 & March \\
\hline 0.031 & 0.032 & 0.746 & April \\
\hline 0.014 & 0.035 & 0.669 & May \\
\hline 0.026 & 0.039 & 0.549 & June \\
\hline 0.047 & 0.036 & 0.815 & July \\
\hline 0.043 & 0.027 & 0.826 & August \\
\hline 0.036 & 0.03 & 0.792 & September \\
\hline 0.039 & 0.018 & 0.935 & October \\
\hline 0.022 & 0.013 & 1.086 & November \\
\hline 0.035 & 0.006 & 1.241 & December \\
\hline 0.035 & 0.040 & 0.936 & The average \\
\hline \multicolumn{4}{|c|}{ Al Andlus JAN -2012 } \\
\hline $\mathrm{SO} 2$ & $\mathrm{O} 3$ & $\mathrm{CO}$ & Date \& Time \\
\hline ppm & $\mathrm{ppm}$ & $\mathrm{ppm}$ & \\
\hline 0.05 & 0.013 & 1.418 & January \\
\hline 0.034 & 0.019 & 0.729 & February \\
\hline 0.028 & 0.028 & 0.655 & March \\
\hline 0.025 & 0.034 & 0.607 & April \\
\hline 0.021 & 0.031 & 0.592 & May \\
\hline 0.033 & 0.03 & 0.86 & June \\
\hline 0.046 & 0.039 & 0.945 & July \\
\hline 0.048 & 0.021 & 0.947 & August \\
\hline 0.046 & 0.024 & 0.937 & September \\
\hline 0.049 & 0.021 & 0.862 & October \\
\hline 0.038 & 0.02 & 0.989 & November \\
\hline 0.05 & 0.013 & 0.972 & December \\
\hline 0.039 & 0.0244 & 0.876 & The average \\
\hline
\end{tabular}

\section{Splining}

In the mathematical field of numerical analysis, spline interpolation is a form of interpolation where the interpolation is a special type of piecewise polynomial called a spline. Spline interpolation is preferred over polynomial interpolation because the interpolation error can be made even when using low degree polynomials for the spline. 


\section{Inverse Distance Weighted Average (IDW)}

- Each input point has local influence that diminishes with distance.

- Estimates are the averages of values at $n$ known points within window.

The linear spline interpolation is: [6]

$$
S_{i}(x)=y_{i}+\frac{y_{i+1}-y_{i}}{x_{i+1}-x_{i}}\left(x-x_{i}\right)
$$

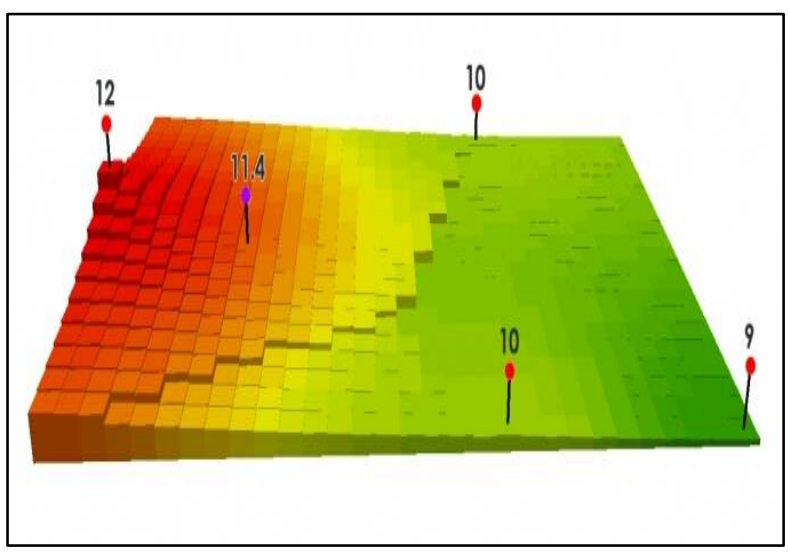

Fig.(2): Show the IDW method [7].

\section{Kriging}

Kriging is an advanced geostatistical procedure that generates an estimated surface from a scattered set of points with z-values. Unlike other interpolation methods supported by ArcGIS Spatial Analyst, to use the Kriging tool effectively involves an interactive investigation of the spatial behavior of the phenomenon represented by the $z$-values before you select the best estimation method for generating the output surface.

\section{Analysis methods :-}

Three methods of interpolation were used in this study (IDW, Kriging, and Spline) in ArcGIS 10.2 program. as in Figs. $(3,4,5,6,7,8)$.

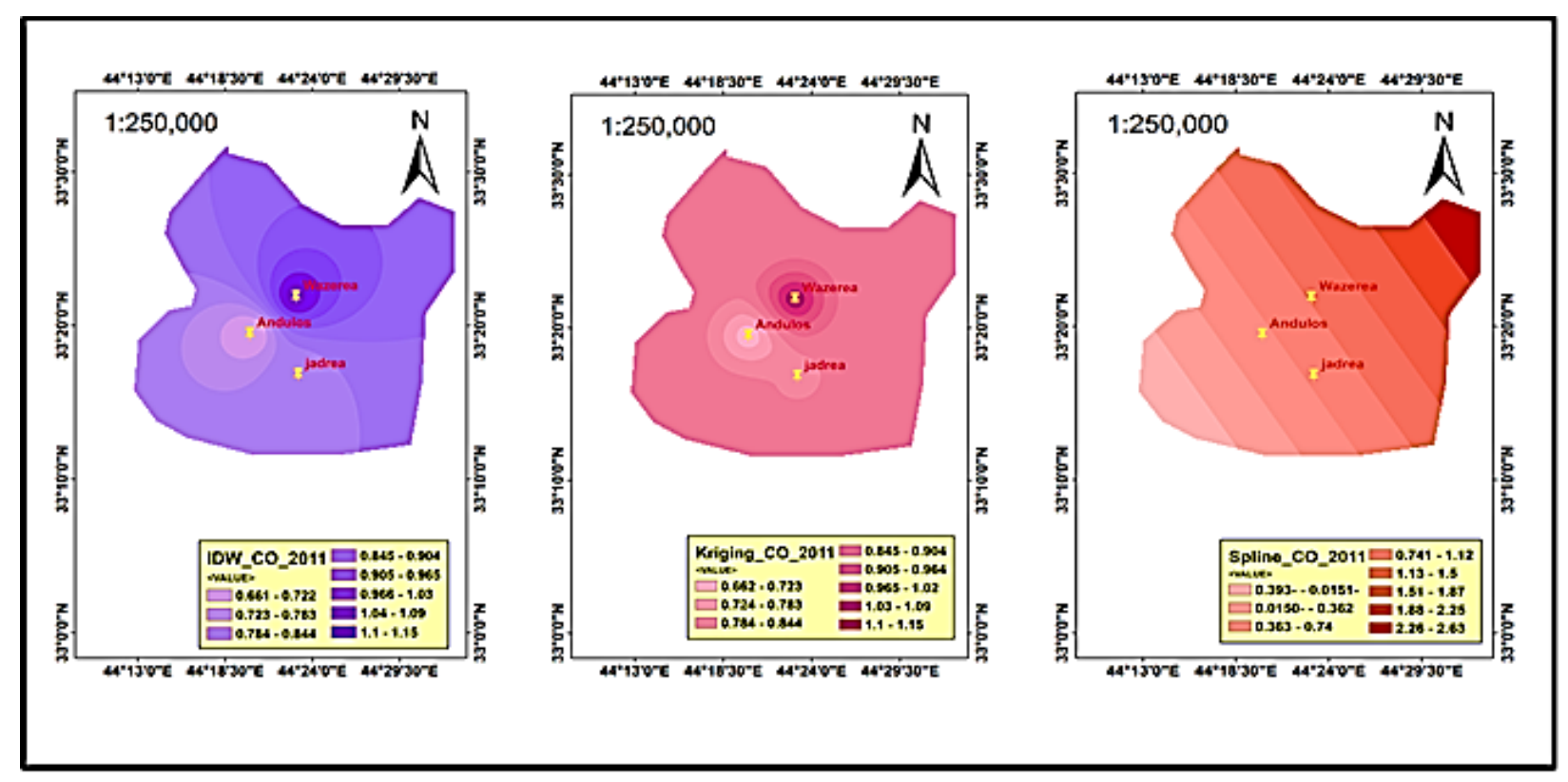

Fig.(3): Show three maps for the distribution of $(C O)$ air pollution in the city of Baghdad in 2011 and using three methods of mathematical interpolation (IDW, Kriging and Spline). 


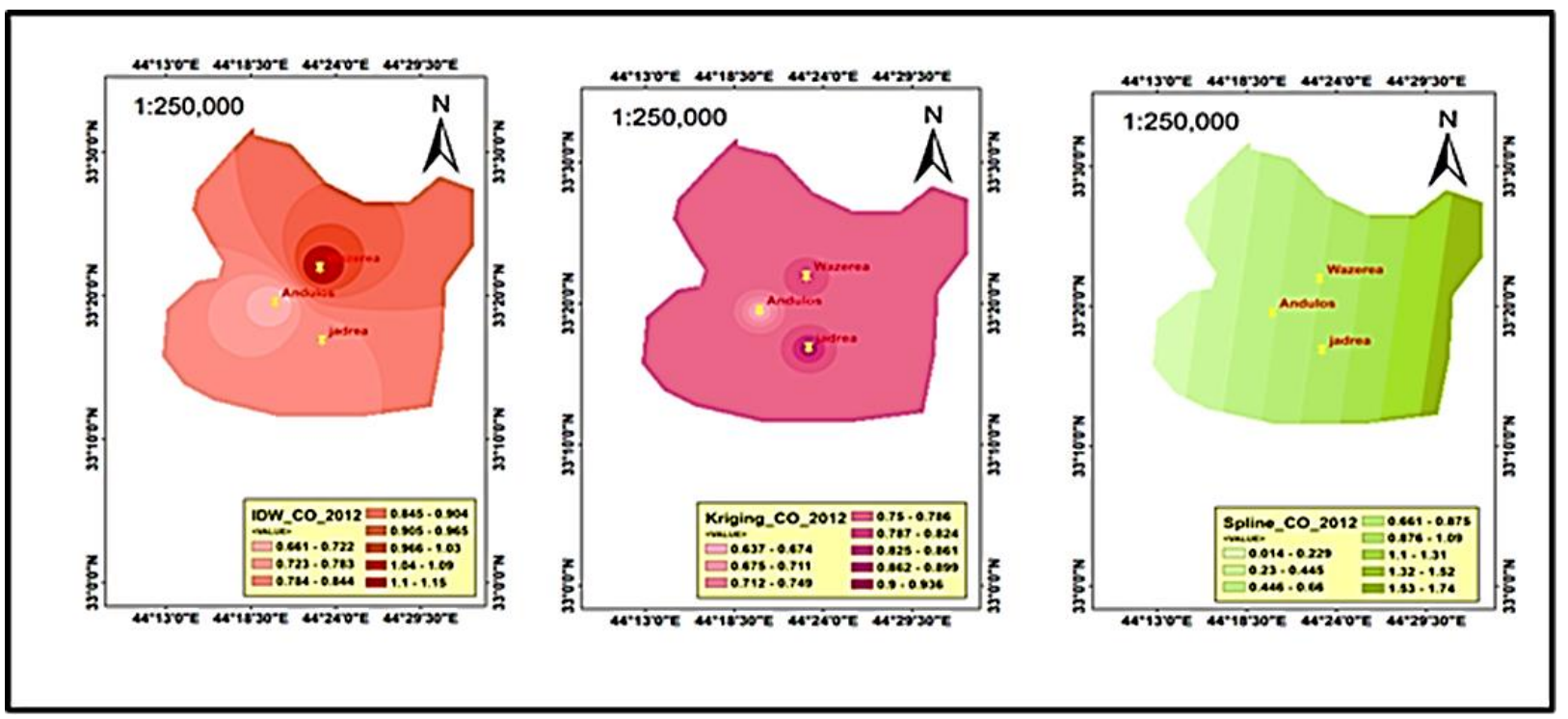

Fig.(4): Show three maps for the distribution of $(C O)$ air pollution in the city of Baghdad in 2012 and using three methods of mathematical interpolation (IDW, Kriging and Spline).

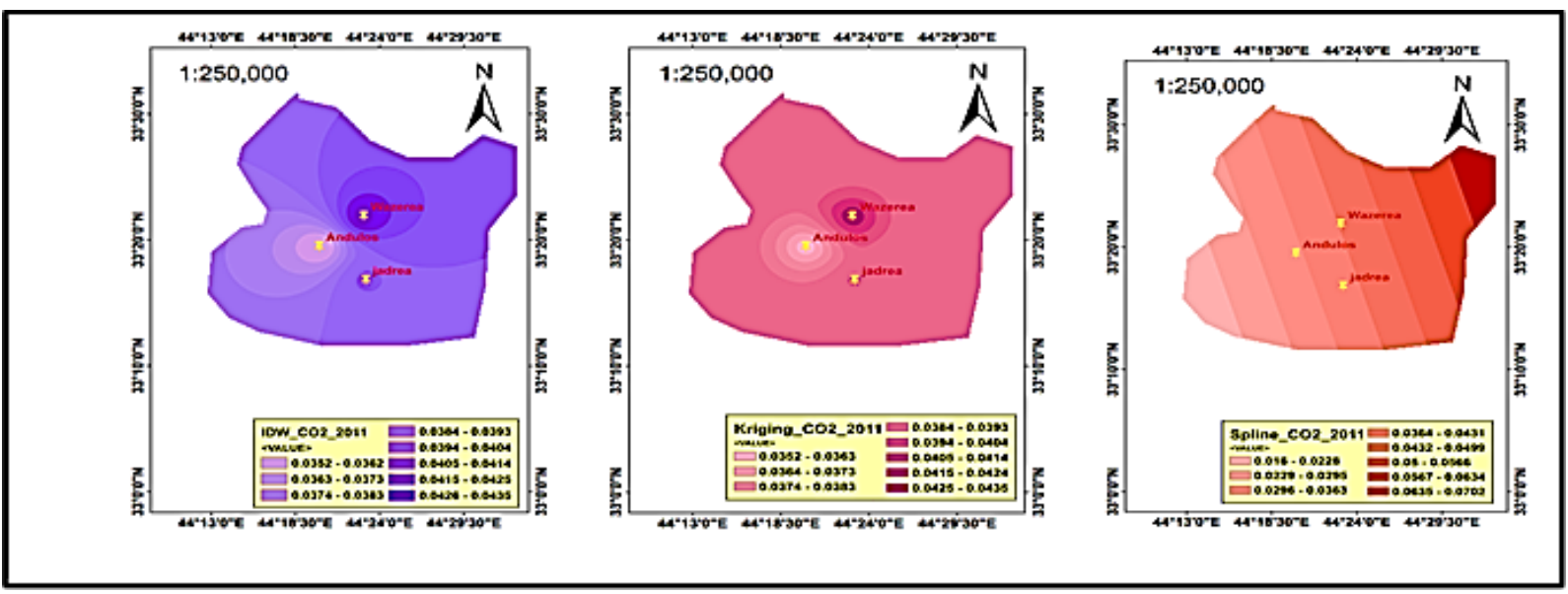

Fig.(5): Show three maps for the distribution of (CO2) air pollution in the city of Baghdad in 2011 and using three methods of mathematical interpolation (IDW, Kriging and Spline).
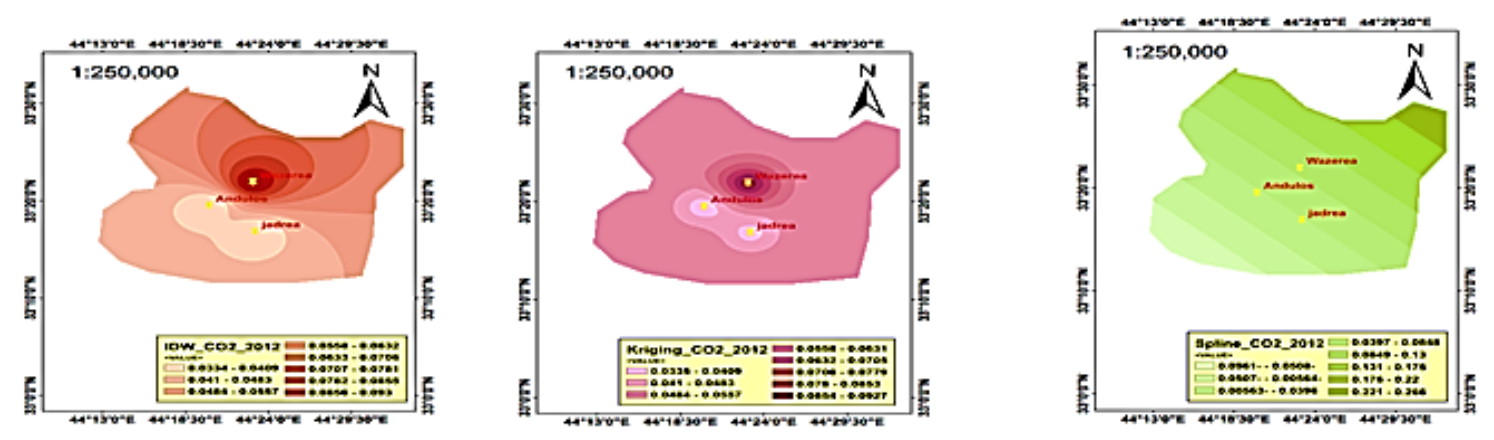

Fig.(6): Show three maps for the distribution of (CO2) air pollution in the city of Baghdad in 2012 and using three methods of mathematical interpolation (IDW, Kriging and Spline). 


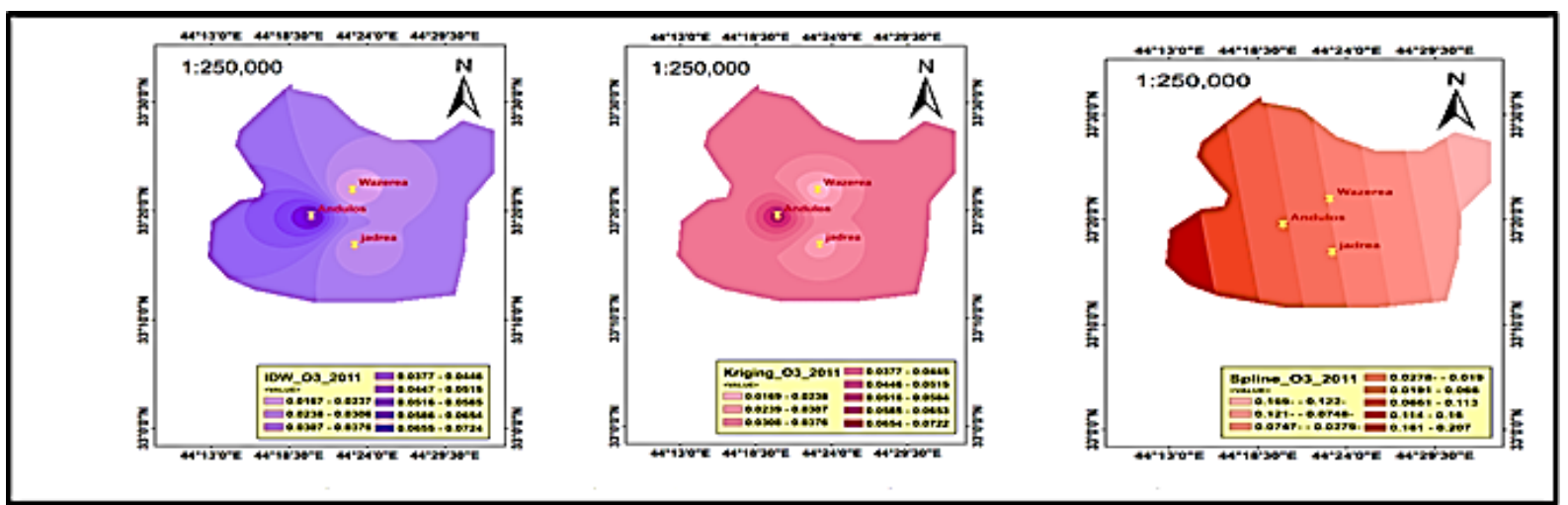

Fig.(7): Show three maps for the distribution of (O3) air pollution in the city of Baghdad in 2011 and using three methods of mathematical interpolation (IDW, Kriging and Spline).

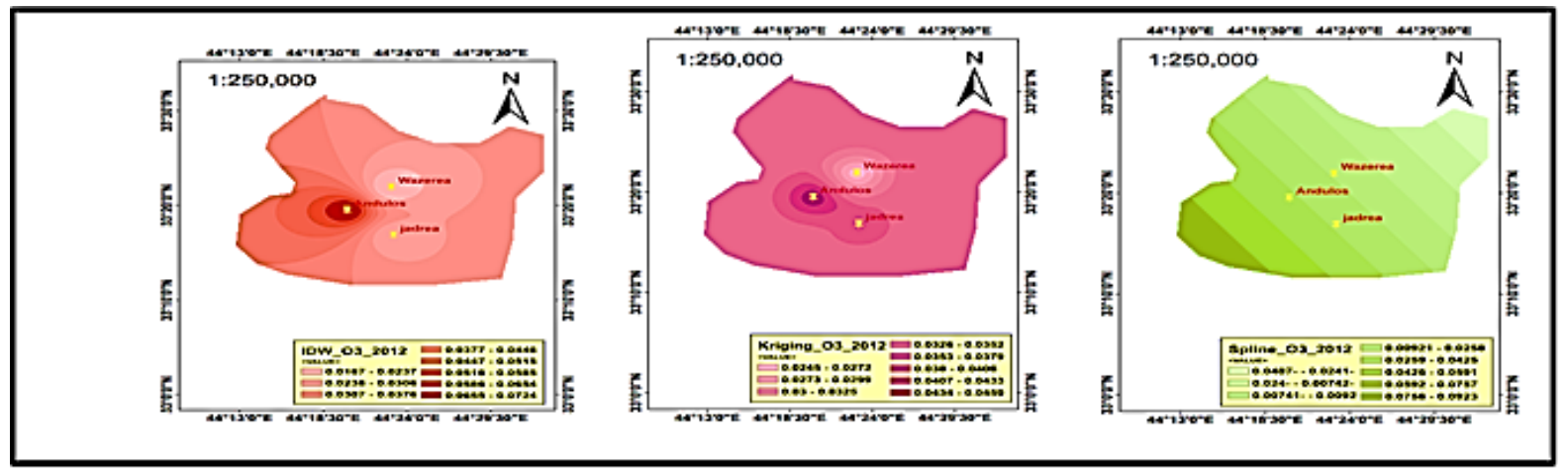

Fig.(8): Show three maps for the distribution of (O3) air pollution in the city of Baghdad in 2012 and using three methods of mathematical interpolation (IDW, Kriging and Spline).

\section{Conclusion}

From the present work, the data measurement for $(\mathrm{CO}, \mathrm{CO} 2, \mathrm{O} 3)$ concentrated we conclude that:

1. The IDW method is the most accurate of the three interpolation methods.

2. Carbon monoxide (CO) is concentrated in the northeastern part of Baghdad (Rusafa district).

3. Carbon dioxide $(\mathrm{CO} 2)$ is concentrated in the northeastern part of Baghdad (Rusafa district).

4. While ozone $(\mathrm{O} 3)$ is concentrated in the south-eastern part of Baghdad (Karkh district).

\section{Recommendations}

1. Increase the number of monitoring stations in Baghdad because their number is small compared to "the size of the city and the population.

2. The need to reduce the value of air pollution in the first gases and carbon dioxide in Baghdad, especially the northeastern part of them.

3. Plant many trees because they have a significant effect on the absorption of the first and second carbon dioxide and increase oxygen.

4. Minimize and prevent the release and release of harmful compounds such as chlorofluorocarbons and halons as these compounds are the most harmful source to the ozone layer.

\section{References}

[1] Hazardous chemicals in human and environmental health (a resource book for school, college and university students) (WHO/PCS/00.1)/2005.

[2] Dr. Abbas Hassan, Air pollution sources and effects ;Babylon of university.

[3] CARBON MONOXIDE POISONING, A guide for GPs and other medical professionals, G26678 BG CO GP Fact Sheet SP A4 AD. indd 1, 2010 .

[4] Prof. Shakhashiri www.scifun.org General Chemistry, CARBON DIOXIDE, CO2, 2008.

[5] Ministry of health and environment Iraq/ unpublished data, 2011, 2012.

[6] Earls, J., and B. Dixon. Spatial interpolation of rainfall data using ArcGIS: A comparative study. ESRI User Conference 2007 Proceedings.

[7] Daly, C., W.P. Gibson, G.H. Taylor, G.L. Johnson, and P. Pasteris. A knowledgebased approach to the statistical mapping of climate. Climate Research 22:99- 113, 2002. 